FACTA UNIVERSITATIS

Series: Mechanical Engineering Vol. 15, Nº 3, 2017, pp. 495 - 506

https://doi.org/10.22190/FUME171001027D

Original scientific paper

\title{
EXPERIMENTAL INVESTIGATION OF THE CONVECTIVE HEAT TRANSFER IN A SPIRALLY COILED CORRUGATED TUBE WITH RADIANT HEATING
}

UDC 662.6

\author{
Milan Đorđević ${ }^{1}$, Velimir Stefanović ${ }^{2}$, Mića Vukić², Marko Mančić \\ ${ }^{1}$ University of Priština, Faculty of Technical Sciences, Kosovska Mitrovica, Serbia \\ ${ }^{2}$ University of Niš, Faculty of Mechanical Engineering, Niš, Serbia
}

\begin{abstract}
The Archimedean spiral coil made of a transversely corrugated tube was exposed to radiant heating in order to represent a heat absorber of the parabolic dish solar concentrator. The main advantage of the considered innovative design solution is a coupling effect of the two passive methods for heat transfer enhancement - coiling of the flow channel and changes in surface roughness. The curvature ratio of the spiral coil varies from 0.029 to 0.234 , while water and a mixture of propylene glycol and water are used as heat transfer fluids. The unique focus of this study is on specific boundary conditions since the heat flux upon the tube external surfaces varies not only in the circumferential direction, but in the axial direction as well. Instrumentation of the laboratory model of the heat absorber mounted in the radiation field includes measurement of inlet fluid flow rate, pressure drop, inlet and outlet fluid temperature and 35 type $K$ thermocouples welded to the coil surface. A thermal analysis of the experimentally obtained data implies taking into consideration the externally applied radiation field, convective and radiative heat losses, conduction through the tube wall and convection to the internal fluid. The experimental results have shown significant enhancement of the heat transfer rate compared to spirally coiled smooth tubes, up to $240 \%$ in the turbulent flow regime.
\end{abstract}

Key Words: Archimedean Spiral Coil, Corrugated Tube, Heat Transfer

Received October 01, 2017 / Accepted November 20, 2017

Corresponding author: Milan Đorđević

Faculty of Technical Sciences, Kneza Miloša 7, 38220 Kosovska Mitrovica, Serbia

E-mail: milan.djordjevic@ pr.ac.rs 


\section{INTRODUCTION}

The utilization of modern paraboloidal concentrators for conversion of solar radiation into heat energy requires the development and implementation of compact and efficient heat absorbers. That is why this research is directed toward an innovative design solution that involves the development of the heat absorber made of spirally coiled tubes with transverse circular corrugations. The main advantage of the considered design solution is a coupling effect of the two passive methods for heat transfer enhancement - coiling of the flow channel and changes in surface roughness. The presence of the superimposed secondary convection in the curved channel flow suppresses axial propagation of the initial turbulent fluctuations so that the curvature stabilizes the flow while the transition from the laminar to the turbulent flow is delayed. On the contrary, the transversal corrugations act as turbulence promoters since the flow turbulence level is increased by a separation and reattachment mechanism. The corrugations act as roughness elements and disturb the existing laminar sublayer. Furthermore, Morton [1] found that heated pipes also develop vortices resulting from a combination of the radial-directional and the downward motions of the fluid particles induced by the displacement of the boundary layer and developed along the pipe. The substantial features of each of these effects (curvature, corrugated wall and heating) are increased heat and mass transfer coefficients due to the cross-sectional mixing of fluid elements as well as enhanced frictional losses. Assessment of the overall impact of the stated effects is impossible either with analytical models or even with numerical ones without the existence of relevant empirical data for their calibration.

Spiral tubes or spiral coils were introduced in $19^{\text {th }}$ century and have been widely used in various thermal engineering applications, such as heat exchangers, electronic cooling, chemical reactors, etc. They have better heat transfer performance and compactness in comparison with commonly used straight tube exchangers, which results in their occupying less space. The transport phenomena occurring in spiral tubes are more complicated than those in straight tubes. Secondary flows observed in the flow patterns, induced by the centrifugal force, significantly affect the flow field and heat transfer.

Most of the studies of thermal-hydraulic processes in the coils have been dedicated to helical coils. Much less work has been reported on the hydrodynamics of flow and heat transfer in spiral coils. The property of a continuously varying curvature along the length makes spiral coil flows never fully developed unlike helical ones. Secondly, the distinction of the flow regime needs specification of two critical Reynolds numbers instead of just one [2]. Naphon and associates [3, 4] experimentally and numerically studied heat transfer and flow developments in the spirally coiled smooth tubes. They stated that the Nusselt number and pressure drop obtained from the spirally coiled tube are for 1.49 and 1.50 times higher than those from the straight tube, respectively, under constant wall temperature boundary condition. Their conclusions could not be considered general since the average Nusselt number and pressure drop are not appropriate for evaluation of heat transfer and flow characteristics of the tubes with a constantly varying curvature. Several numerical studies [57] have been published, which examined the flow and heat transfer phenomena in spiral tubes. These papers investigate the laminar flow of Newtonian fluids in coils, while those that investigate turbulent flow conditions are rare. Moreover, all take into account two common thermal boundary conditions - constant wall temperature and constant heat flux.

Even though the interest in spiral coiled systems is on the rise, there are still very few published articles on spiral coil tubes. They are less popular compared to helical ones, 
which have attracted major attention in the study of coiled tubes for heat transfer. There is very little information about the Nusselt number as well as correlations, and in the absence of appropriate correlations, the traditional approach is to use the correlations developed for circular or helical tubes with an average curvature.

Examining the research studies on thermal-hydraulic processes in straight tubes with high values of relative roughness it can be concluded that the appropriate correlations for determining the coefficients of friction and heat transfer in the laminar flow regime almost do not exist. Furthermore, the results of different authors differ significantly in general conclusions. It can be concluded that there is a lack of data for a range of geometrical parameters and the Reynolds number for transversely corrugated straight pipes having large relative roughness. Moreover, no reference concerning hydrodynamics and heat transfer in spiral tube coils with transverse corrugations was found. Another specific aspect of this investigation is that the heat exchanger in the model under consideration is subjected to a radiant asymmetrical heat flux, while most of the existing correlations for convective heat transfer are valid for flow in channels with direct, uniform heating.

\section{EXPERIMENT}

The objective of this paper was to experimentally study the distribution of the convective heat transfer in a spirally coiled corrugated tube exposed to radiant heating that is characteristic of parabolic dish solar concentrators. Investigation of the influence of hydraulic, physical and thermal conditions, as well as the geometry of the spirally coiled corrugated heat absorber, on the local intensity of heat transfer and pressure drop was conducted using modern experimental methods.

The Archimedean spiral, with a pitch slightly larger than the maximal outside diameter of the corrugated coiling tube, was selected out of different types of spirals in order to achieve the most favorable ratio of active surface area and the total volume of the heat absorber in the parabolic dish receiver. The geometrical characteristics and experimental configurations of the transversely corrugated straight pipe and the transversely corrugated Archimedean spiral coil are shown in Figs. 1 and 2, respectively, while Table 1 shows geometrical parameters of the tested configuration.

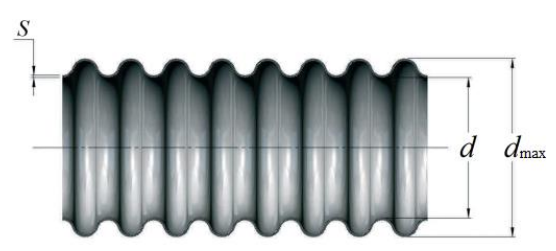

Fig. 1 Profile of transverse corrugated pipe made of stainless steel AISI 304 [8]

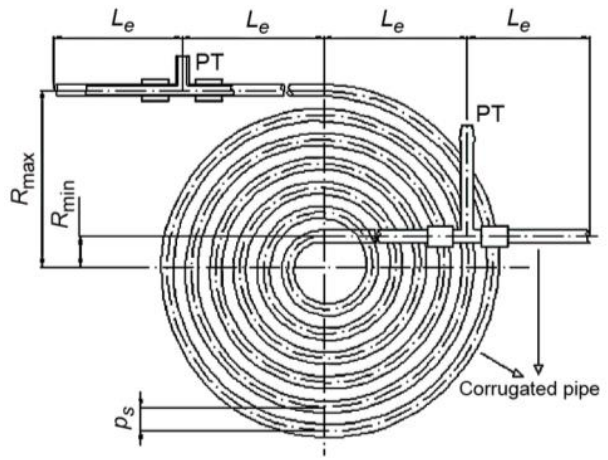

Fig. 2 Geometry and configuration of transversely corrugated Archimedean spiral coil 
In order to simulate the real working conditions of the heat absorber an experimental installation is constructed. The installation consists of a spirally coiled corrugated tube of heat absorber with an accompanying flow loop and a radiant heating system. The schematic diagram of the hydraulic system is shown in Fig. 3. The entire experimental apparatus enables variations of the following operating parameters: 1) intensity of the incident radiant heat flux; 2) flow rate and flow direction of the working fluid, and 3) angle of inclination of the spiral heat exchanger in relation to the horizontal plane.

Table 1 Geometrical parameters of the tested configuration

\begin{tabular}{lclllcll}
\hline & Transversely corrugated straight tube & \multicolumn{5}{c}{ Transversely corrugated Archimedean spiral coil } \\
\hline$d$ & 9.3 & $\mathrm{~mm}$ & minimum internal diameter & $R_{\min }$ & 25 & $\mathrm{~mm}$ & minimum radius of the coil \\
$d_{0}$ & 11.7 & $\mathrm{~mm}$ & maximum internal diameter & $R_{\max }$ & 202 & $\mathrm{~mm}$ & maximum radius of the coil \\
$d_{\max }$ & 12.2 & $\mathrm{~mm}$ & maximum external diameter & $N$ & 13 & - & number of coil turns \\
$s$ & 0.25 & $\mathrm{~mm}$ & wall thickness & $L$ & 9.324 & $\mathrm{~m}$ & length of the coil \\
$e$ & 1.2 & $\mathrm{~mm}$ & corrugation depth & $L_{\mathrm{e}}$ & 0.5 & $\mathrm{~m}$ & length of entrance section \\
$p_{\mathrm{c}}$ & 4.2 & $\mathrm{~mm}$ & corrugation pitch & $p_{\mathrm{s}}$ & 13.6 & $\mathrm{~mm}$ & spiral coil pitch \\
\hline
\end{tabular}

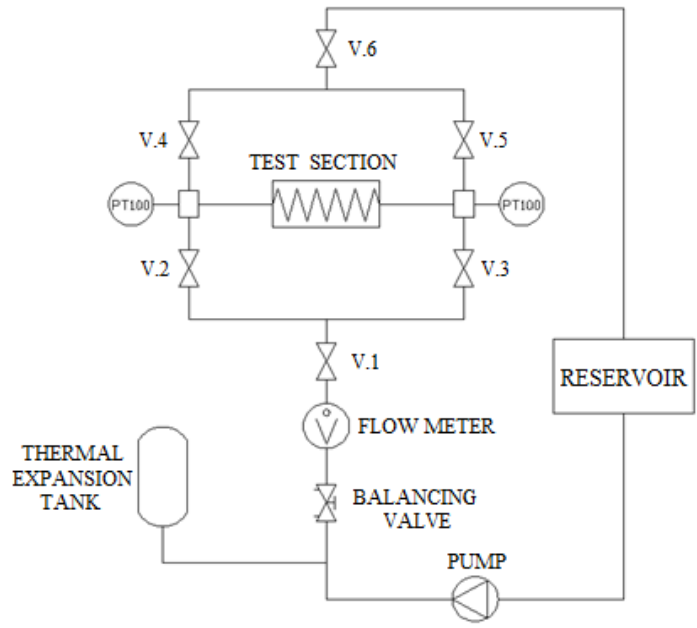

Fig. 3 Schematic diagram of the test loop

In addition to water, a mixture of propylene glycol and water $(90 \%$ and $10 \%$ by volume, respectively) was also used to expand the experimental range. The volume flow rate is measured with the flask and the ultrasonic flow meter (Kamstrup, type 66W02F1318), while the flow is regulated by the TA-STAD balancing valve. Pressure drops were measured with a hydrostatic pressure gauge (up to a maximum pressure drop of $20 \mathrm{kPa}$ ) and a differential pressure gauge (for pressure drop values greater than $20 \mathrm{kPa}$ ). Measuring the temperature of the working fluid at the inlet and outlet of the coil was performed with two Pt100 temperature sensors positioned in the mixing chambers.

In order to measure variations of the tube wall temperature along the axis of the tube, as well as its circumferential direction, a total number of 35 type $\mathrm{K}$ thermocouples (Chromel-Alumel, wire diameter $\phi 0.22 \mathrm{~mm}$ ) were located on the outside surface of the 
tube in a special arrangement so that there was one thermocouple station in the middle of each turn of the spiral coil.

At some thermocouple stations, either two or four thermocouples were welded to the tube surface using a capacitor discharge welding machine, which is specially designed and operated for research purposes. Peripheral locations at these stations were specified as: location $\mathrm{A}\left(\theta=0^{\circ}\right)$ corresponds to the outer side of the tube cross section (the furthest from the curvature center), location $\mathrm{B}\left(\theta=90^{\circ}\right)$ corresponds to the side of the tube cross section which is directly subjected to radiant flux, location $\mathrm{C}\left(\theta=180^{\circ}\right)$ corresponds to the inner side of the tube cross section (the closest to the curvature center) and location $\mathrm{D}(\theta$ $=270^{\circ}$ ) receives heat only by air convection and conduction through the tube wall. Since the tube is corrugated, the thermocouples were located both at the basic, minimum, diameter of the tube, as well as on the tops of the corrugations, at the maximum diameter of the tube. The schematic diagrams of thermocouple arrangements around the circumference of the tube cross section are shown in Figs. 4 and 5. The additional 9 thermocouples were located in the middle of the remaining turns of the spiral coil on the minimum tube diameter. After the thermocouples were connected, the coil surface was coated with temperature resistant flat black paint "Pyromark 2500", whose minimum guaranteed absorptance is 0.9 [9].

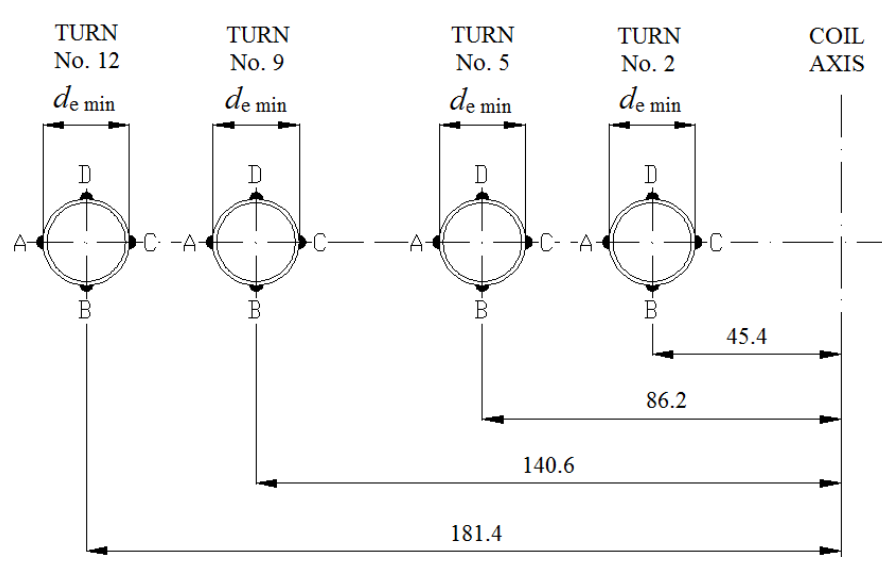

Fig. 4 Circumferential locations of thermocouples at the minimum diameter of the tube

The outputs of thermocouples were connected to two input modules NI 9213, with 16 channels both, and one input module NI 9211 with 4 channels, which allow simultaneous recording of signals from 36 thermocouples. The input modules were connected to the computer via a ethernet chassis NI cDAQ-9188, while the software package LabVIEW 2013 was used for recording temperature values and generation of reports.

The incident heat flux upon the tube external surfaces varies both in the circumferential and axial direction. It was obtained by the radiant heating system, which is specifically designed for the purposes of this experimental research. Detailed analyses of the radiant heat flux produced by the quartz heating system and radiant absorption characteristics of the corrugated curved tubes could be found in our previous papers [10, 11]. 


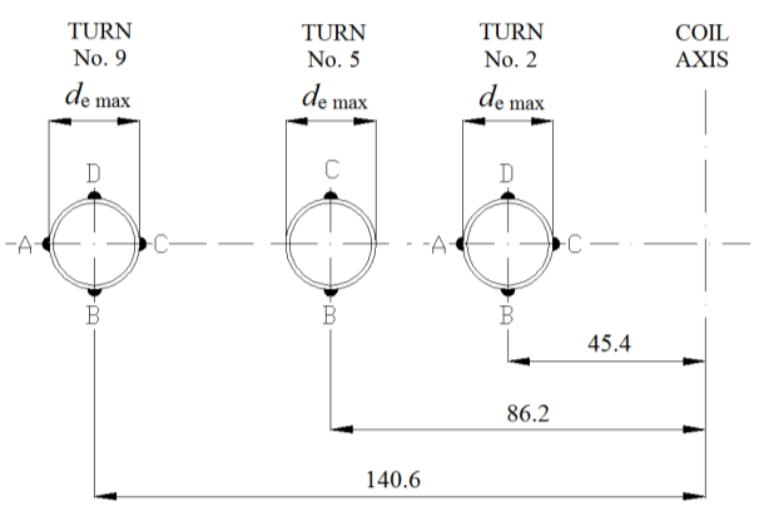

Fig. 5 Circumferential locations of thermocouples at the maximum diameter of the tube

Kline and McClintock [12] method was used to estimate uncertainties involved in the calculation of the heat transfer coefficient and Nu number. They vary up to $3.72 \%$ and $3.85 \%$ for calculated values of the heat transfer coefficient and Nu number, respectively.

\section{THERMAL ANALYSIS}

The flow in the heated curved tube with corrugations is very complex, characterized by the existence of the secondary flows with recirculation cells in the plane normal to the direction of axial velocity and formation of vortices in the corrugations. The combination of these factors, along with nonuniformity of the boundary conditions, both in the axial direction and around the circumference of the tube, as well as the uncertainty in determining the local fluid conditions, make solving the problem of heat transfer by analytical methods impossible, thus necessitating an experimental procedure.

The method of calculation of each of the quantities necessary for estimating the heat transfer coefficient at the inner surface of the tube is presented. The local values of heat transfer coefficient $h_{\mathrm{i}}$ and $\mathrm{Nu}$ number for any given axial $(z)$ and circumferential $(\theta)$ location (denoted as $\left.\right|_{z, \theta}$ ) at the inner surface of the tube were calculated according to:

$$
\begin{aligned}
& \left.h_{\mathrm{i}}\right|_{z, \theta}=\frac{\left.q_{\mathrm{i}}\right|_{z, \theta}}{\left.T_{\mathrm{i}}\right|_{z, \theta}-\left.T_{\mathrm{b}}\right|_{z}} \\
& \left.\mathrm{Nu}\right|_{z, \theta}=\frac{\left.\left.h_{\mathrm{i}}\right|_{z, \theta} \cdot d_{\mathrm{i}}\right|_{z}}{\left.\lambda_{\mathrm{f}}\right|_{z}}
\end{aligned}
$$

where $T_{\mathrm{i}}$ is the inner surface local temperature of the tube, $d_{\mathrm{i}}$ is tube internal diameter and $\lambda_{\mathrm{f}}$ is the thermal conductivity of the transport fluid. Bulk temperature of the fluid at some axial location is defined as:

$$
T_{\mathrm{b}}=\frac{1}{V A_{\mathrm{c}}} \int_{A_{\mathrm{c}}} T \vec{U} \mathrm{~d} A
$$

where $\vec{U}$ is the local velocity vector, $T$ is the local fluid temperature and $V$ is the average velocity at the considered cross-section, whose area is $A_{\mathrm{c}}$ : 


$$
V=\frac{1}{A_{\mathrm{c}}} \int_{A_{\mathrm{c}}} \vec{U} \mathrm{~d} A_{\mathrm{c}}
$$

Thermophysical properties of water $[13,14]$ and a mixture of propylene glycol and water $(90 \%$ and $10 \%$ by volume, respectively) $[14,15]$ are treated as temperature-dependent and were obtained as polynomial functions of temperature.

\subsection{Calculation of total heat input}

The net heat flux at the outer surface at any specific axial location along the spiral and at any angular position $\left(\left.q_{\mathrm{o}}\right|_{z, \theta}\right)$ can be considered equal to the net heat flux at the corresponding radial location of the inner surface of the tube $\left(q_{\mathrm{i}} \mathrm{|}_{z, \theta}\right)$. This assumption is justified by a relatively small thickness of the wall, as well as relatively large values of the heat transfer coefficient that characterize all the flow regimes in the considered geometry. Heat losses and gains from the outer surface of the coil are due to convection $\left.q_{\mathrm{conv}}\right|_{z, \theta}$ and radiation $\left.q_{\mathrm{rad}}\right|_{z, \theta}$ to the outside environment. These heat losses will also be a function of the axial and circumferential position around the tube cross section, as the tube surface temperature is not uniform.

The net heat flux at the outer surface is given by:

$$
\left.q_{\mathrm{o}}\right|_{z, \theta}=\left.q_{\mathrm{abs}}\right|_{z, \theta}-\left.q_{\mathrm{conv}}\right|_{z, \theta}-\left.q_{\mathrm{rad}}\right|_{z, \theta}
$$

where $q_{\mathrm{abs}} \mathrm{I}_{z, \theta}$ is absorbed radiative heat flux. Analytical expressions for the calculation of $\left.q_{\text {conv }}\right|_{z, \theta}$ and $\left.q_{\text {rad }}\right|_{z, \theta}$ are:

$$
\begin{gathered}
\left.q_{\text {conv }}\right|_{z, \theta}=h_{\mathrm{o}}\left(\left.T_{\mathrm{o}}\right|_{z, \theta}-T_{\text {cav }}\right) \\
\left.q_{\text {rad }}\right|_{z, \theta}=\sigma \varepsilon\left(\left.T_{\mathrm{o}}^{4}\right|_{z, \theta}-T_{\text {amb }}^{4}\right)
\end{gathered}
$$

where $h_{\mathrm{o}}$ is the local value heat transfer coefficient at the outer surface of the tube, $T_{\mathrm{cav}}$ and $T_{\mathrm{amb}}$ represent the temperature of the air in the cavity of the receiver and ambient, respectively, while $\sigma$ and $\varepsilon$ denote the Stefan-Boltzmann constant and emissivity, respectively.

Heat transfer coefficient at the outer surface of the tube wall $h_{\mathrm{o}}$ was determined according to the relation given by Churchill and Chu [16]:

$$
h_{\mathrm{o}}=\left[0.60+0.387 \cdot \mathrm{Ra}^{1 / 6} /\left(1+\left(0.559 / \mathrm{Pr}_{\text {air }}\right)^{9 / 16}\right)^{8 / 27}\right]^{2} \frac{\lambda_{\text {air }}}{d_{\text {ekv }}}
$$

where the Grashof and Rayleigh number are defined as:

$$
\begin{gathered}
\mathrm{Gr}=d_{\text {ekv }}{ }^{3} \rho_{\text {air }}{ }^{2} g \cdot \Delta T \beta_{\text {air }} / \mu_{\text {air }}{ }^{2} \\
\mathrm{Ra}=\mathrm{Gr} \cdot \mathrm{Pr}_{\text {air }}
\end{gathered}
$$

In previous equations $d_{\text {ekv }}$ is the equivalent external tube diameter, $g$ is the Earth gravity acceleration, $\Delta T$ is the temperature difference between the boundary layer and the bulk fluid, while $\lambda_{\text {air }}, \rho_{\text {air }}, \beta_{\text {air }}, \mu_{\text {air }}$ and $\operatorname{Pr}_{\text {air }}$ are thermal conductivity, density, volumetric temperature expansion coefficient, dynamic viscosity and Prandtl number of air, respectively. 
Assuming stationary heat transfer, an energy balance can provide a relationship between the net value of the heat flux at the outer surface of the tube and the thermal power of the absorber formulated by the parameters of the working fluid:

$$
\left.\int_{0}^{2 \pi} \int_{0}^{L} q_{\mathrm{o}}\right|_{z, \theta} d_{\mathrm{o}} \mathrm{d} \theta \mathrm{d} z=\dot{V} \rho_{\mathrm{ave}} c_{\text {ave }}\left(T_{\text {out }}-T_{\text {in }}\right)
$$

where $\rho_{\text {ave }}, c_{\text {ave }}, T_{\text {out }}$ and $T_{\text {in }}$ are average density, average specific heat capacity, outlet and inlet temperature of transport fluids, respectively.

Based on the previously defined energy balance, the bulk fluid temperature at some axial location at a distance $l$ from inlet can be calculated as:

$$
\left.\int_{0}^{2 \pi} \int_{0}^{l} q_{\mathrm{o}}\right|_{z, \theta} d_{\mathrm{o}} \mathrm{d} \theta \mathrm{d} z=\dot{V} \rho_{\mathrm{ave}} c_{\mathrm{ave}}\left(\left.T_{\mathrm{b}}\right|_{l}-T_{\mathrm{in}}\right), \quad 0 \leq l \leq L
$$

\subsection{Heat conduction in tube wall}

The inner surface local temperature of tube $T_{\mathrm{i}} \mathrm{I}_{z, \theta}$ could be determined based on the corresponding values of the outer surface local temperature of tube $T_{\mathrm{o}} \mathrm{I}_{z, \theta}$ and the local net heat flux at outer surface $\left.q_{\mathrm{o}}\right|_{z, \theta}$ according to the expression:

$$
\left.T_{\mathrm{i}}\right|_{z, \theta}=\left.T_{\mathrm{o}}\right|_{z, \theta}-\frac{\left.\left.q_{\mathrm{o}}\right|_{z, \theta} \cdot d_{\mathrm{i}}\right|_{z} \cdot \ln \left(\frac{\left.d_{\mathrm{o}}\right|_{z}}{\left.d_{\mathrm{i}}\right|_{z}}\right)}{2 \lambda_{\mathrm{w}}}
$$

where $\lambda_{\mathrm{w}}$ denotes the thermal conductivity of the tube wall.

\section{RESULTS}

Based on the experimental tests of thermal-hydraulic processes in spirally coiled corrugated tube of the heat absorber exposed to radiant heating, a systematic study of the thermal characteristics of the considered heat exchanger was carried out. The results presented are based on 146 complete series of measurements for different experimental conditions. The determination of the flow stability criteria and of the critical Re numbers has already been shown in our previous work [17].

A mixture of propylene glycol and water ( $90 \%$ and $10 \%$ by volume, respectively) was used as a working fluid in the Reynolds number range $\mathrm{Re} \approx 56-1734$ and Prandl number range $\operatorname{Pr} \approx 36.4-255$, while water was used in the ranges $\operatorname{Re} \approx 1225-16731$ и $\operatorname{Pr} \approx 3.0-7.0$. $\operatorname{Pr}$ number variation of working fluids is in accordance with the range of temperature that characterizes the experimental conditions. The selected Re number ranges guarantee a separate existence of all the three flow regimes for all the values of curvature ratio $\delta$ ( $\delta=d_{\mathrm{e}} / 2 R$, while $R$ is the radius of curvature), which varies in the range $\delta=0.023-0.186$ and is determined by the constructive characteristics of the spiral heat exchanger.

The local values of $\mathrm{Nu}$ number were calculated both at the minimum diameter of the tube, as well as on the corrugation crests. In order to determine the values of the peripherally averaged $\mathrm{Nu}$ number most accurately, the locations of thermocouples at minimum and maximum diameter on the same coil turn were positioned at the axial distance equal to the half of the corrugation pitch. 
The correlations between the peripherally averaged $\mathrm{Nu}$ number and the $\mathrm{Re}$ and $\mathrm{Pr}$ numbers and the basic geometrical parameter of spiral $(\delta)$ were obtained by a multiple nonlinear regression analysis, assuming simple exponential models. Proposed correlations for laminar, transitional and turbulent flow regimes, as well as the ranges of their applicability, are represented by Eqs. (14-16), respectively:

$$
\mathrm{Nu}=0.556 \operatorname{Re}^{0.61} \operatorname{Pr}^{0.174} \delta^{0.164}
$$

$100<\operatorname{Re}<1200 ; 40<\operatorname{Pr}<190 ; 0.023<\delta<0.146$

$$
\mathrm{Nu}=0.363 \operatorname{Re}^{0.641} \operatorname{Pr}^{0.3} \delta^{0.11}
$$

$1250<\operatorname{Re}<3200 ; 6<\operatorname{Pr}<90 ; 0.023<\delta<0.146$

$$
\mathrm{Nu}=0.289 \operatorname{Re}^{0.654} \operatorname{Pr}^{0.43} \delta^{0.07}
$$

$$
3500<\operatorname{Re}<15000 ; 4<\operatorname{Pr}<7 ; 0.023<\delta<0.146
$$

Figures 6-8 show the comparisons of experimental data and the best fit lines obtained by least squares analysis of the points predicted by corresponding correlations.

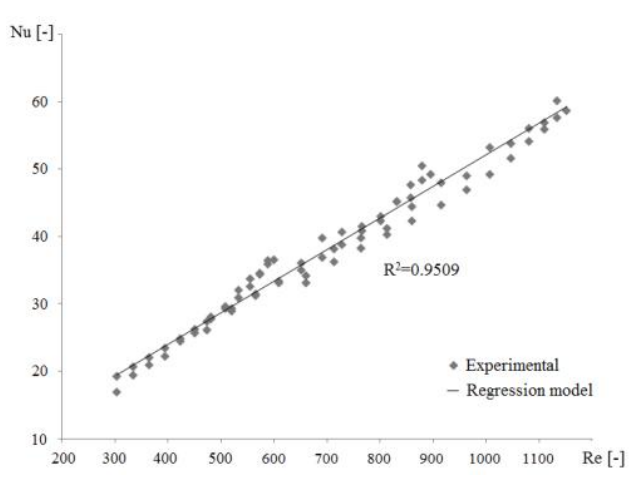

Fig. 6 Graph of the regression model: laminar flow

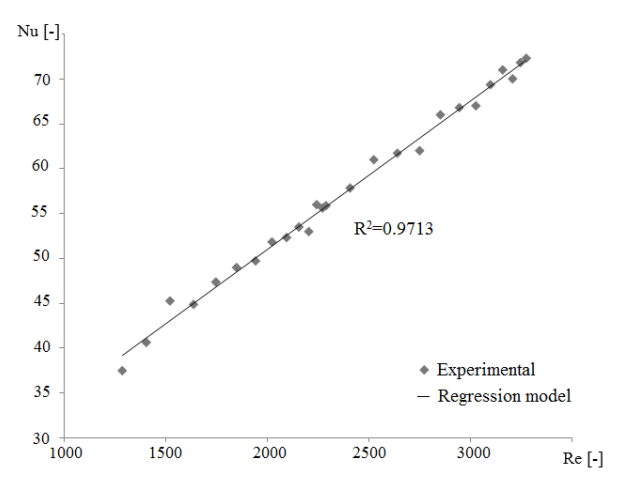

Fig. 7 Graph of the regression model: trasitional flow

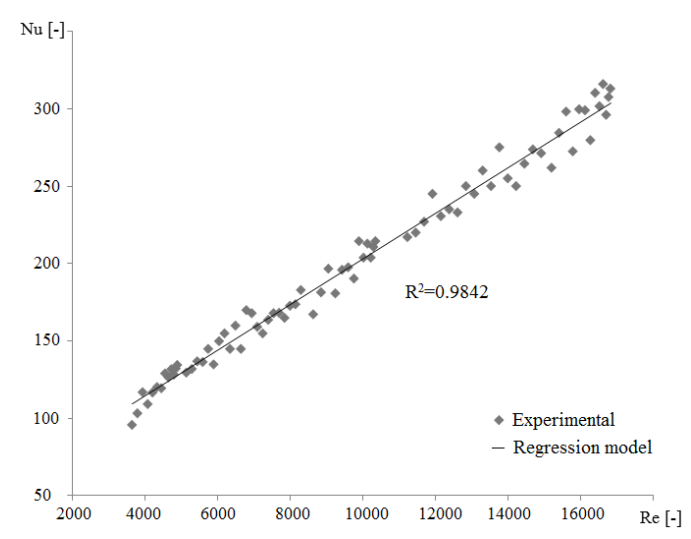

Fig. 8 Graph of the regression model - turbulent flow 
The maximum deviations of the predictions are $8 \%$ in the laminar, $7 \%$ in the transitional and $14 \%$ in the turbulent flow regime.

After obtaining power-law dependences, the possibility of applying some of the momentum-heat transfer analogies to spirally coiled corrugated tubes was considered. This is a more fundamental approach since analogies are most physically founded and rest on a more sound theoretical ground than widely used power-law formulas.

Di Piazza and Ciafolo [18] indicated that the modified Reynolds analogy is applicable in smooth curved pipes with constant curvature. It is valid in the average and only approximately is valid locally (analogy is less applicable for a higher curvature). On the other hand, Bergles and Morton [19] have shown that for the surfaces characterized with large relative roughness no unique relation between friction coefficient and heat transfer could be formulated.

An additional problem in attempting to formulate the momentum-heat transfer analogy in this study is the formulation and determination of the local values of the friction coefficient in the spiral because of its dependence on the constantly variable curvature of the flow channel. Using the normalized values of the friction coefficient in the Petukhov and Gnielinski analogies yields values of the peripherally averaged $\mathrm{Nu}$ number with significantly larger deviations compared to the predictions obtained by power-law models. This leads to the conclusion that the momentum-heat transfer analogies cannot be applied in general in the tubes with a variable radius of curvature that are characterized by high values of relative roughness.

\section{CONCLUSIONS}

The empirical power-low formulas have been suggested to indicate the dependency of the peripherally averaged $\mathrm{Nu}$ number on $\mathrm{Re}$ and Pr numbers and on the curvature in the spirally coiled corrugated tubes exposed to radiant heating. A large database reduces the influence of random errors, thus making a statistical approach highly reliable. The obtained correlations for heat transfer are applicable in wide ranges of flow, physical and geometric parameters. The accuracy of the obtained correlations can be compared with that of the correlation in the literature about research studies of similar processes, which justifies the use of the statistical method.

The suggested formulas indicate the effects of the considered parameters for the heat transfer rate. A relatively high exponent value of the Re number in the laminar flow regime indicates the dominant influence of the secondary flows on heat transfer which significantly increases the heat transfer rate. The Reynolds number exponent in the turbulent flow regime is lower than the value of 0.8 , otherwise typical of simple geometries. This is consistent with the previous investigation of Ciofalo and Collins [20] who consider the value of the exponent for complex flow channel geometries where detachment and reattachment of the boundary layer exist. The exponent value of curvature $\delta$ decreases with the increase in the Re number, which indicates that the secondary flows in the turbulent regime have a relatively small effect on the heat transfer.

The experimentally obtained peripherally averaged $\mathrm{Nu}$ number was compared to the corresponding one in the smooth spiral coil for identical boundary conditions [21]. The $\mathrm{Nu}$ number in the corrugated spiral coil is not significantly higher in the laminar flow 
regime and the increase is slightly more than $50 \%$ at the end of the laminar flow range $(\operatorname{Re} \approx 1300)$. The enhancement of the heat transfer in the corrugated spiral coil is considerably conditioned by the value of the Re number, so that the increase in the Nu number at the end of the test range in the turbulent flow regime $(\operatorname{Re} \approx 15000)$ is about $240 \%$.

Developing flow along with secondary flows make the development of the peripherally averaged $\mathrm{Nu}$ number rather oscillatory. It makes difficult to represent the differences in distribution of the peripherally averaged Nu number along the spiral axial coordinate for the cases of inflow to outermost or innermost spiral turn. Those differences are relatively small and the proposed power-law formulas cannot account for the complexity of the real functional dependences.

The proposed formulas are applicable for heat transfer in Archimedean spiral coils made of transversally corrugated tubes. They cannot be compared to others because, to the best of our knowledge, this has not been reported before. These values characterize the examined geometry of the corrugations and, according to our assessment, could be applied when geometric ratio $p_{\mathrm{c}} / e$ ranges from 3 to 5 . The future work should be pointed to the effects of the basic corrugation parameters on the heat transfer rate.

\section{REFERENCES}

1. Morton, B. R., 1959, Laminar convection in uniformly heated horizontal pipes at low Rayleigh numbers, Quarterly Journal of Mechanics and Applied Mathematics, 12(4), pp. 410-420.

2. Ali, S., Seshadri, C., 1971, Pressure drop in Archimedean spiral tubes, Industrial and Engineering Chemistry Process Design and Development, 10(3), pp. 328-332.

3. Naphon, P., Wongwises, S., 2002, An experimental study on the in-tube convective heat transfer coefficients in a spiral coil heat exchanger, International Communications in Heat and Mass Transfer, 29(6), pp. 797-809.

4. Naphon, P., Suwagrai, J., 2007, Effect of curvature ratios on the heat transfer and flow developments in the horizontal spirally coiled tubes, International Journal of Heat and Mass Transfer, 50(3), pp. 444-451.

5. Nakayama, A., Kokubo, N., Ishida, T., Kuwahara, F., 2000, Conjugate numerical model for cooling a fluid flowing through a spiral coil immersed in a chilled water container, Numerical Heat Transfer, Part A, 37(2), pp. 155-165.

6. Kurnia, J.C., Sasmito, A.P., Mujumdar, A.S., 2011, Numerical investigation of laminar heat transfer performance of various cooling channel designs, Applied Thermal Engineering, 31(6), pp. 1293-1304.

7. Sasmito, A. P., Kurnia, J.C., Wang, W., Jangam, S.V., Mujumdar, A.S., 2012, Numerical analysis of laminar heat transfer performance of in-plane spiral ducts with various cross-sections at fixed cross-section area, International Journal of Heat and Mass Transfer, 55(21), pp. 5882-5890.

8. ***, Pliable Corrugated Stainless Steel Resistant to Corrosion CSST Tubes for Plumbing, Heating Systems and Thermal Solar Plants, http://www.eurotis.it (Last Access: 13.07.2017)

9. Ho, C.K., Mahoney, A.R., Ambrosini, A., Bencomo, M., Hall, A., Lambert, T.N., 2012, Characterization of Pyromark 2500 for high-temperature solar receivers, Proc. $6^{\text {th }}$ International Conference on Energy Sustainability of ASME, San Diego, USA, pp. 509-518.

10. Đorđević, M., Stefanović, V., Pavlović, S., Mančić, M., 2015, Numerical analyses of the radiant heat flux produced by quartz, heating system, Proc. $3^{\text {rd }}$ International Conference Mechanical Engineering in XXI Century, Niš, Serbia, pp. 75-80.

11. Đorđević, M., Stefanović, V., Kalaba, D., Mančić, M, Katinić, M., 2017, Radiant absorption characteristics of corrugated curved tubes, Thermal Science, DOI: 10.2298/TSCI160420263D.

12. Kline, S., McClintok, F., 1953, Describing uncertainties in single-sample experiments, Mechanical Engineering, 75(1), pp. 3-8.

13. ***, 2007, IAPWS industrial formulation for the thermodynamic properties of water and steam (IAPWS-IF97), The IAPWS-IF97.

14. Đorđević, M., Stefanović, V., Vukić, M., Mančić, M., 2017, Experimental investigation on the convective heat transfer in a spirally coiled corrugated tube, Proc. 18th Symposium on Thermal Science and Engineering of Serbia, Soko Banja, Serbia. 
15. ***, 2001, Engineering and operating guide for DOWFROST and DOWFROST HD inhibited propylene glycol-based heat transfer fluids, Dow Chemical Company, USA, available at: http://msdssearch.dow.com/ PublishedLiteratureDOWCOM/dh_010e/0901b8038010e417.pdf?filepath=heattrans/pdfs/noreg/180-01286. pdf\&fromPage=GetDoc (Last Access: 15.10.2017)

16. Churchill, S.W., Chu, H.H.S., 1975, Correlating equations for laminar and turbulent free convection from a horizontal cylinder, International Journal of Heat and Mass Transfer, 18, pp. 1323-1329.

17. Đorđević, M., Stefanović, V., Mančić, M., 2016, Pressure drop and stability of flow in Archimedean spiral tube with transverse corrugations, Thermal Science, 20(2), pp. 579-591.

18. Di Piazza I., M. Ciofalo, 2010, Numerical Prediction of turbulent flow and heat transfer in helically coiled pipes, International Journal of Thermal Sciences, 49, pp. 653-663.

19. Bergles, A. E., Morton, H. L., 1965, Survey and evaluation of techniques to augment convective heat transfer, Technical Report NO. 5382-34, Massachusetts Institute of Technology, USA.

20. Ciofalo, M., Collins, M.W., 1989, $k$ - $\varepsilon$ predictions of heat transfer in turbulent recirculating flows using an improved wall treatment, Numerical Heat Transfer, 15, pp. 21-47.

21. Đorđević, M., Stefanović, V., Vukić, M., Mančić, M., 2016, Numerical investigation on the convective heat transfer in a spiral coil with radiant heating, Thermal Science, 20(Suppl. 5), pp. S1215-S1226. 